\title{
Multi-particulate Drug Delivery Systems of Methylphenidate Hydrochloride: Optimization of Formulation Using Statistical Experimental Design
}

\author{
Bala Vishnu Priya Mukkala', T. E. G. K. Murthy², Prameela Rani Avula ${ }^{3}$
}

${ }^{1}$ Formulation Research and Development, RA Chem Pharma Ltd., Hyderabad, Telangana, India, ${ }^{2}$ Department of Pharmaceutics, Bapatla College of Pharmacy, Bapatla, Guntur, Andhra Pradesh, India, ${ }^{3}$ Department of Pharmaceutics, Acharya Nagarjuna University, Guntur, Andhra Pradesh, India

\section{Abstract}

Introduction: The objective of the present investigation was to develop a multiparticulate modified release system of methylphenidate hydrochloride $(\mathrm{HCl})$ generating biphasic release profile from single core. Materials and Methods: Wurster (bottom spray fluid bed coating) process was employed to develop extended release (ER) pellets of methylphenidate $\mathrm{HCl}$. Impact of various formulation variables was assessed using statistical interpretation such as analysis of variance. A $3^{2}$ (two factor, three level) factorial design was employed to study the effect of independent variables (ER polymer [Eudragit RSPO/ Eudragit RLPO/Ethocel] concentration and plasticizer concentration), on dependent variables (drug release at $3^{\text {rd }}$ and $8^{\text {th }} \mathrm{h}$ ). Optimization was done by fitting experimental data to the software program (Design Expert). The design space for formulation variables (ER polymer concentration and plasticizer concentration) and its influence on drug release was developed. Results and Discussion: Fabricated pellets were characterized for various physicochemical parameters. In vitro release data observed from the optimized formulation was fitted into various kinetic equations. The optimized formulation showed desired drug release at both $3^{\text {rd }}$ and $8^{\text {th }} \mathrm{h}$ as $60.33 \% \pm 0.58 \%$ and $93.33 \% \pm 0.58 \%$, respectively. Capsules showed an initial burst release preceding a more gradual ER phase following first order kinetics and Fickian diffusion process. Conclusion: Methylphenidate HCl ER pellets were successfully developed by employing bottom spray fluid bed coating (Wurster) technique. The factorial experimental design facilitated the formulation and optimization of modified drug delivery system of methylphenidate $\mathrm{HCl}$.

Key words: Factorial design, methylphenidate hydrochloride, modified drug delivery systems, pellets

\section{INTRODUCTION}

$\mathrm{I}$ $\mathrm{n}$ the present era, multiparticulate dosage forms are gaining interest over single unit dosage forms, owing to their potential advantages include no risk of dose dumping, reduced risk of local irritation, less inter- and intra subject variability and increased bioavailability. Wurster (bottom spray fluid bed) process is one of the most promising techniques for fabrication of pellets, as it promotes uniform coating which leads to an efficient and predictable drug release. ${ }^{[1-3]}$

Quality by design is a holistic and proactive approach to support the pharmaceutical development in a more scientific, riskbased manner, by restricting the flexibility in the manufacturing process to ensure predetermined product specifications. It helps to assess the critical material attributes and critical process parameters that impacting the predefined critical quality attribute (CQAs). The design space concept is introduced as "the multidimensional combination and interaction of input variables (e.g., materials attributes) and process parameters that have been demonstrated to provide assurance of quality." Using this approach, it is essential to define

Address for correspondence:

Bala Vishnu Priya Mukkala, Formulation Research and Development, RA Chem Pharma Ltd., Hyderabad, Telangana, India.

E-mail: vishnupriya.mukkala@gmail.com

Received: 21-06-2017

Revised: 11-07-2017

Accepted: 17-07-2017 
the relationship between critical formulation/process parameters and CQAs. ${ }^{[4]}$

Response surface methodology (RSM) is one of the popular methods in the development and optimization of drug delivery systems. Based on the principles of design of experiments (DOEs), the methodology involves the use of various types of experimental designs, generation of polynomial mathematical relationships, and mapping of the response over the experimental domain to select the optimum formulation. Central composite design, three level factorial design, Box-Behnken design, and D-optimal design are the different types of RSM designs available for statistical optimization of the formulations. Factorial design is one type of RSM design enables, all factors to be varied simultaneously, allowing quantification of the effects caused by independent variables and interactions between them. Factorial design requires fewer experimental runs, less time and thus provides a cost-effective technique than the conventional processes of formulating and optimization of dosage forms. Hence, factorial design was selected as DOE. ${ }^{[5]}$

Methylphenidate hydrochloride $(\mathrm{HCl})$ is an amphetaminelike central nervous system stimulant, commonly used to treat attention deficit hyperactivity disorder (ADHD) in children, adolescents and adults. Its $\mathrm{HCl}$ salt is freely soluble in water, stable and well absorbed from the intestinal tract, with a short elimination half-life (i.e., 3-4 h). These favorable properties combined with a low dose and also need to decrease the dosing frequency, make methylphenidate as an ideal candidate for development of a new generation of modified release formulation, which offers the equivalent efficacy of repeated administration of immediate release product. ${ }^{[6]}$

The present investigation aimed to fabricate a methylphenidate $\mathrm{HCl}$ extended-release (ER) pellets. Preliminary trials were executed with various concentrations of seal coating polymer $(3-10 \% \mathrm{w} / \mathrm{w})$ and various types and concentration of enteric coating polymers (Eudragit L30 D 55 and hydroxypropyl methylcellulose HPMC AS $15-25 \% \mathrm{w} / \mathrm{w})$. Optimization of the methylphenidate $\mathrm{HCl}$ ER pellets was done by employing factorial design as optimization technique, with constraints on release of drug after $3^{\text {rd }} \mathrm{h}(55-65 \%)$. The independent variables for this study were concentration of release retardant polymers (Eudragit RSPO, Eudragit RLPO, and ethyl cellulose) and plasticizer (triethyl citrate $[\mathrm{TEC}]$ ). The dependent variables studied were drug release at $3^{\text {rd }} \mathrm{h}(55-65 \%)$ and $8^{\text {th }} \mathrm{h}(85-100 \%)$.

\section{MATERIALS AND METHODS}

\section{Materials}

Methylphenidate $\mathrm{HCl}$ was obtained from RA Chem Pharma Ltd., Hyderabad, as gift sample, sugar spheres (Arun Pharma), hypromellose (Dow Chemical's), povidone (BASF), talc (Luzenac), Eudragit RSPO (Evonik), Eudragit
RLPO (Evonik), Ethocel 45 cps (Colorcon), Eudragit L 30 D55 (Evonik), HPMCAS (Shin Etsu), TEC (Merck), isopropyl alcohol (Avantor), purified water and empty hard gelatin capsule shells size 1 (ACG) were used as received.

\section{Methods}

\section{Drug-excipient compatibility studies}

Methylphenidate $\mathrm{HCl}$ and selected excipients were subjected for drug excipient compatibility study. The drug and individual excipients were intimately mixed in equal parts by weight and filled in glass vials stoppered with teflon plugs and sealed with aluminum seals. These samples were kept in incubators at $40^{\circ} \mathrm{C} / 75 \% \mathrm{RH}$. Samples were analyzed for the solid state property of the drug in the blended mixtures using differential scanning colorimeter (DSC) at initial and 1 month $\left(40^{\circ} \mathrm{C} / 75 \% \mathrm{RH}\right)$.

\section{Preparation of methylphenidate $\mathrm{HCI}$ ER pellets by Wurster process}

Methylphenidate $\mathrm{HCl}$ ER pellets were prepared by employing bottom - spray fluid bed (Wuster) coating process (Glatt GPCG 1.1). The dosage form was designed to obtain the biphasic release profile from single population of pellets comprising immediate release and ER portions. Dose was distributed among the two portions equally, i.e., $50 \%$ as immediate release (IR) portion and second part as ER portion.

Drug loaded pellets were prepared by spraying the aqueous drug dispersion over nonpariel seeds (sugar spheres [20\#-25\# ASTM]) employing Wurster process (bottom spray fluid bed coating technology). The drug dispersion was coated onto sugar spheres using $1.0 \mathrm{~mm}$ of spray nozzle with a spray rate of 2-6 g/min, $0.8-1.0 \mathrm{~kg} / \mathrm{cm}^{2}$ of atomization air pressure, $45-60 \mathrm{cfm}$ of air volume, and product temperature $38-42^{\circ} \mathrm{C}$. The drug dispersion was sprayed until get desired weight gain. The drug loaded pellets were dried for $10 \mathrm{~min}$ at $38-42^{\circ} \mathrm{C}$. Further, aqueous seal coating dispersion was coated onto the drug loaded pellets employing similar process parameters as drug loading process except $40-45^{\circ} \mathrm{C}$ as product temperature. Seal coated pellets were dried for $10 \mathrm{~min}$ at $40-45^{\circ} \mathrm{C}$. Hydro-alcoholic (IPA:water - 80:20) ER coating dispersion was coated over the seal coated pellets using Wurster process at a spray rate of $4-8 \mathrm{~g} / \mathrm{min}$ and $34-38^{\circ} \mathrm{C}$ as product temperature. The ER coated pellets were dried for $15 \mathrm{~min}$ at $34-38^{\circ} \mathrm{C}$. Further, the aqueous enteric coating dispersion was coated onto the ER coated pellets at $28-32^{\circ} \mathrm{C}$ as product temperature and at a spray rate of $2-6 \mathrm{~g} / \mathrm{min}$. Enteric coated pellets were subjected for drying at $35^{\circ} \mathrm{C}$ for $15 \mathrm{~min}$. Finally, drug dispersion of immediate release portion was coated over the enteric coated pellets using similar process parameters as that of earlier. Immeadiate release (IR) drug loaded pellets were dried for $10 \mathrm{~min}$ at a temperature of $38-42^{\circ} \mathrm{C}$. Final pellets were sifted through \#16-\#20 ASTM mesh to separate the fines and agglomerates and collect the desired portion. 


\section{Experimental design}

In preliminary trials, the formulation variables in each step of the manufacturing process were evaluated for their significance by analysis of variance (ANOVA). Finally, found that the type and concentrations of ER coating polymer, plasticizer concentration had a significant impact on drug release of prepared pellets.

The factorial design was used to evaluate the effect of independent variables (ER polymer and plasticizer concentration) on responses/dependent variables (drug release at $3^{\text {rd }} \mathrm{h}\left[Y_{1}\right]$ and $8^{\text {th }} \mathrm{h}\left[Y_{2}\right]$ ) of methylphenidate $\mathrm{HCl} \mathrm{ER}$ pellets. A two-factor, three-level design is used for exploring quadratic response surfaces and constructing second order polynomial models with Design Expert (Stat-Ease).

ANOVA is inevitably linked to experimental design, which was used to analyze the significance of the model and each selected response. It was also generate polynomial equations. The response $\left(Y_{1}\right)$ in each trial was estimated by carrying out a multiple factorial regression analysis using the generalized quadratic model:

$Y_{1}=b_{0}+b_{1} X_{1}+b_{2} X_{2}+b_{1} b_{2} X_{1} X_{2}$

Where, $Y_{1}$ is the measured response associated with each factor level combination; $b_{0}$ is an intercept; $b_{1}$ and $b_{2}$ are regression coefficients computed from the observed experimental values of $Y_{1}$; and $X_{1}$ and $X_{2}$ are the coded levels of independent variables.

After fitting the response data in experimental design as in Table 1, the experimental results were analyzed by ANOVA. It demonstrated the various statistical parameters such as $b$ coefficients, $F$ values, $P$ values of model terms and correlation coefficient $\left(R^{2}\right)$ values. The suitability of model was authenticated by the predicted and adjusted $R^{2}$ values. ${ }^{[7]}$

\section{Optimization of ER coating composition}

The independent variables in ER coating were type and concentration of ER polymer, i.e., Eudragit RSPO, Eudragit RLPO, ethyl cellulose and concentration of plasticizer (TEC). Both variables were studied at three levels $(-1,0,+1)$.
Percentage of drug release at $3^{\text {rd }} \mathrm{h}\left(Y_{1}\right)$ and percentage of drug release at $8^{\text {th }} \mathrm{h}\left(Y_{2}\right)$ were selected as responses. The impact of each selected ER polymer and plasticizer concentration on responses were studied and optimized individually.

\section{Evaluation of methylphenidate HCI ER pellets}

\section{Micromeritic properties ${ }^{[8]}$}

Bulk density (BD), tapped density (TD), and Hausner ratio (HR) of pellets were determined. BD and TD were determined by USP method I using a TD tester.

$\mathrm{BD}=$ Weight of the sample (g)/untapped volume ( $\mathrm{ml})$,

$\mathrm{TD}=$ Weight of the sample $(\mathrm{g}) /$ tapped volume $(\mathrm{ml})$,

HR was calculated using following formulae:

$\mathrm{HR}=\mathrm{TD} / \mathrm{BD}$

Where TD and BD are tapped and bulk densities.

\section{Assay $^{[9]}$}

Methylphenidate $\mathrm{HCl}$ ER pellets equivalent to $20 \mathrm{mg}$ of methylphenidate $\mathrm{HCl}$ were transferred into $100 \mathrm{~mL}$ volumetric flask, added diluent (methanol:acetonitrile: $\mathrm{pH} 4.0$ sodium acetate buffer at a ratio of 4:3:3) and sonicated for $15 \mathrm{~min}$ to dissolve, made the volume up to the mark with diluent. Transferred $10 \mathrm{~mL}$ of this solution to $20 \mathrm{~mL}$ volumetric flask and made the volume up to the mark. The solution was filtered through $0.45 \mu$ nylon membrane filter. The following chromatographic conditions were employed for analysis:

- Column: Kromosil 60, CN $250 \mathrm{~mm} \times 4.6 \mathrm{~mm}, 5 \mu \mathrm{m}$ or its equivalent

- Injection volume: $50 \mu \mathrm{L}$

- Flow rate: $1.5 \mathrm{~mL} / \mathrm{min}$

- Detector: Ultraviolet, $210 \mathrm{~nm}$

- Runtime: 10 min.

Calculations:

Assay of methylphenidate $\mathrm{HCl}$ :

$$
\begin{aligned}
& =\frac{A_{T}}{A_{S}} \times \frac{W_{S}}{100} \times \frac{10}{20} \times \frac{100}{W_{T}} \times \frac{20}{10} \times \frac{P}{100} \times A . W \\
& =----\mathrm{mg} / \text { capsule }
\end{aligned}
$$

\section{Table 1: Variables in factorial design}

\begin{tabular}{lccc} 
Factor & \multicolumn{3}{c}{ Levels used, actual (coded) } \\
\cline { 2 - 4 } & Low (-1) & Medium (0) & High (+) \\
\hline ER polymer concentration $(\% \mathrm{w} / \mathrm{w})\left(X_{1}\right)$ & 2 & 3.5 & 5 \\
Plasticizer concentration $(\% \mathrm{w} / \mathrm{w})\left(X_{2}\right)$ & 10 & 20 & 30 \\
\hline Dependent variables & Constraints & \\
\hline$Y_{1}=\%$ drug release at $3^{\text {rd }} \mathrm{h}$ & $55 \leq Y_{1} \leq 65$ & \\
$Y_{2}=\%$ drug release at $8^{\text {th }} \mathrm{h}$ & $85 \leq Y_{2} \leq 100$ & \\
\hline
\end{tabular}

ER: Extended release 
$\%$ of label amount $=\frac{\text { Assay of methylphenidate }}{\text { Label claim }} \times 100$

Where,

$A_{T}=$ Peak area of methylphenidate $\mathrm{HCl}$ obtained from the sample solution,

$A_{S}=$ Average peak area of methylphenidate $\mathrm{HCl}$ obtained from the standard solution,

$W_{S}=$ Weight of methylphenidate $\mathrm{HCl}$ working standard taken in $\mathrm{mg}$,

$W_{T}=$ Weight of sample taken in $\mathrm{mg}$,

$P=$ Potency of methylphenidate $\mathrm{HCl}$ working standard used (on as is basis),

$A=$ Average weight of the fill contents of capsules in $\mathrm{mg}$.

\section{In vitro drug release studies ${ }^{[10]}$}

The methylphenidate $\mathrm{HCl}$ ER pellets equivalent to $40 \mathrm{mg}$ methylphenidate $\mathrm{HCl}$ were accurately filled into size 1 hard gelatin capsules and evaluated for in vitro drug release studies, which were performed using USP Type I dissolution test apparatus. The volume of the dissolution medium was $500 \mathrm{ml}$ with a stirring speed of $75 \mathrm{rpm}$, and the temperature was maintained at $37^{\circ} \mathrm{C} \pm 0.5^{\circ} \mathrm{C}$. These conditions were kept constant for all dissolution studies. The study was carried out in $0.01 \mathrm{~N} \mathrm{HCl}$ for $2 \mathrm{~h}$ followed by $\mathrm{pH} 6.8$ phosphate buffer at $1,2,3,4,6$, and $8 \mathrm{~h} .10 \mathrm{ml}$ of sample was withdrawn periodically and replaced with equal volume of fresh dissolution medium. The collected samples were filtered through $0.45 \mu$ nylon membrane filter and analyzed to assess the $\%$ drug dissolved by employing same chromatographic conditions as that of assay.

The $\%$ labeled amount of methylphenidate $\mathrm{HCl}$ dissolved at respective time intervals $(\mathrm{Dn})$ was estimated from following formulae:

$$
=\frac{A_{T}}{A_{S}} \times \frac{W_{S}}{100} \times \frac{5}{25} \times \frac{500}{\mathrm{LC}} \times \frac{P}{100} \times 100=-----\%
$$

Where,

$A_{T}=$ Peak area of methylphenidate $\mathrm{HCl}$ obtained from the sample solution,

$A_{S}=$ Average peak area of methylphenidate $\mathrm{HCl}$ obtained from the standard solution,

$W_{S}=$ Weight of methylphenidate $\mathrm{HCl}$ working standard taken in $\mathrm{mg}$,

$P=$ Potency of methylphenidate $\mathrm{HCl}$ working standard used (on as is basis),

$\mathrm{LC}=$ Label claim.

Calculate the correction factor $(\mathrm{CFn})$ at each time point by using the following formula:

$$
C F n=\frac{D n}{500} \times 10
$$

\section{Drug release kinetics $^{[11]}$}

The drug release kinetics and mechanism from the formulations were studied by fitting the data obtained from the in vitro release study into several mathematical equations.

\section{RESULTS AND DISCUSSION}

\section{Drug excipient compatibility studies}

From the DSC thermograms, at the initial stage, the onset melting point of active pharmaceutical ingredient (API) and composite blend were observed at $220.34^{\circ} \mathrm{C}$ and $160.26^{\circ} \mathrm{C}$, respectively, and peak melting point of API and composite blend were observed at $222.59^{\circ} \mathrm{C}$ and $164.64^{\circ} \mathrm{C}$, respectively. From the endothermic peaks after 4 weeks storage at $40^{\circ} \mathrm{C} / 75 \% \mathrm{RH}$, the onset melting point of API and composite blend were observed at $222.23^{\circ} \mathrm{C}$ and $183.16^{\circ} \mathrm{C}$, respectively, and peak melting point of API and composite blend were observed at $224.38^{\circ} \mathrm{C}$ and $171.01{ }^{\circ} \mathrm{C}$, respectively [Figure 1]. Hence, it was concluded that there was no interaction between the drug substance and the chosen excipients. Hence, these excipients were considered for the use in the development of the formulation.

\section{Preparation of methylphenidate $\mathrm{HCI}$ ER pellets}

Methylphenidate $\mathrm{HCl}$ ER pellets were prepared by employing Wurster process. The impact of formulation variables at each stage such as seal coating (seal coating polymer concentration), ER coating (ER coating polymer type, concentration and plasticizer concentration), and enteric coating (enteric coating polymer type and concentration, plasticizer concentration) on release rate constant were evaluated in preliminary trials and results were interpreted by ANOVA. Process parameters were selected and established based on prior experience.

From the obtained results, $5 \% \mathrm{w} / \mathrm{w}$ HPMC E5 as seal coating polymer, 20\% w/w Eudragit L 30 D 55 as enteric coating polymer with $20 \% \mathrm{w} / \mathrm{w}$ plasticizer concentration with respect to the polymer. ER coating polymer type (Eudragit RLPO, Eudragit RSPO and ethyl cellulose) and concentration (2\%, $3.5 \%$ and $5 \% \mathrm{w} / \mathrm{w})$, plasticizer concentration $(10 \%, 20 \%$ and $30 \% \mathrm{w} / \mathrm{w}$ with respect to the polymer concentration) were identified as high-risk variables have a potential impact on drug release. Hence these factors were studied by a twofactor, three-level factorial experimental design, individually.

\section{Data analysis and model validation}

\section{Fitting of data to the model}

Two factors with three levels factorial experimental design for triplicates require 27 experiments, the independent 
Table 2: Observed responses in factorial design for methylphenidate $\mathrm{HCI}$ ER pellets

\begin{tabular}{|c|c|c|c|c|c|c|c|}
\hline \multicolumn{2}{|c|}{ Independent variables } & \multicolumn{6}{|c|}{ Dependent variables/responses } \\
\hline \multirow{2}{*}{$\begin{array}{l}\text { ER polymer } \\
\text { concentration } \\
(\% w / w)\left(X_{1}\right)\end{array}$} & \multirow{2}{*}{$\begin{array}{c}\text { Plasticizer (TEC) } \\
\text { concentration } \\
(\% w / w)\left(X_{2}\right)\end{array}$} & \multicolumn{3}{|c|}{$\%$ Drug release at $3^{\text {rd }} \mathrm{h}\left(Y_{1}\right)$} & \multicolumn{3}{|c|}{$\%$ Drug release at $8^{\text {th }} \mathrm{h}\left(Y_{2}\right)$} \\
\hline & & $\begin{array}{c}\text { Eudragit } \\
\text { RSPO }\end{array}$ & $\begin{array}{c}\text { Eudragit } \\
\text { RLPO }\end{array}$ & Ethocel & $\begin{array}{c}\text { Eudragit } \\
\text { RSPO }\end{array}$ & $\begin{array}{c}\text { Eudragit } \\
\text { RLPO }\end{array}$ & Ethocel \\
\hline 5 & 20 & $56 \pm 2.2$ & $69 \pm 1.3$ & $53 \pm 0.8$ & $89 \pm 2.7$ & $93 \pm 0.4$ & $81 \pm 2.6$ \\
\hline 3.5 & 20 & $61 \pm 0.6$ & $77 \pm 2.1$ & $55 \pm 0.5$ & $93 \pm 1.3$ & $97 \pm 1.5$ & $85 \pm 0.3$ \\
\hline 2 & 20 & $65 \pm 1.9$ & $83 \pm 2.7$ & $59 \pm 1.4$ & $95 \pm 0.9$ & $99 \pm 0.6$ & $90 \pm 0.9$ \\
\hline 2 & 20 & $65 \pm 1.3$ & $82 \pm 1.2$ & $59 \pm 1.6$ & $96 \pm 0.8$ & $99 \pm 0.8$ & $91 \pm 0.7$ \\
\hline 3.5 & 10 & $59 \pm 0.8$ & $74 \pm 2.9$ & $52 \pm 0.9$ & $92 \pm 1.1$ & $95 \pm 1.2$ & $84 \pm 1.5$ \\
\hline 2 & 30 & $68 \pm 1.4$ & $85 \pm 1.1$ & $60 \pm 0.7$ & $96 \pm 0.5$ & $100 \pm 0.9$ & $91 \pm 1.3$ \\
\hline 2 & 30 & $67 \pm 1.6$ & $85 \pm 0.9$ & $61 \pm 1.0$ & $97 \pm 0.2$ & $99 \pm 0.5$ & $92 \pm 0.8$ \\
\hline 3.5 & 20 & $60 \pm 0.7$ & $77 \pm 0.8$ & $54 \pm 1.1$ & $94 \pm 0.6$ & $98 \pm 1.4$ & $85 \pm 1.6$ \\
\hline 5 & 10 & $54 \pm 1.9$ & $66 \pm 1.5$ & $51 \pm 2.1$ & $87 \pm 1.6$ & $90 \pm 2.1$ & $79 \pm 2.8$ \\
\hline 2 & 10 & $64 \pm 0.9$ & $80 \pm 1.1$ & $57 \pm 1.7$ & $95 \pm 0.8$ & $98 \pm 1.7$ & $87 \pm 1.1$ \\
\hline 3.5 & 10 & $57 \pm 1.1$ & $73 \pm 1.8$ & $53 \pm 1.4$ & $91 \pm 1.1$ & $96 \pm 0.7$ & $83 \pm 1.4$ \\
\hline 3.5 & 20 & $60 \pm 0.4$ & $78 \pm 0.9$ & $55 \pm 0.9$ & $93 \pm 1.4$ & $98 \pm 1.2$ & $84 \pm 0.6$ \\
\hline 3.5 & 30 & $62 \pm 1.2$ & $80 \pm 1.5$ & $58 \pm 0.6$ & $94 \pm 1.2$ & $100 \pm 1.6$ & $88 \pm 1.6$ \\
\hline 3.5 & 30 & $63 \pm 1.6$ & $79 \pm 1.2$ & $57 \pm 1.2$ & $93 \pm 0.7$ & $101 \pm 0.5$ & $88 \pm 0.7$ \\
\hline 5 & 20 & $55 \pm 2.4$ & $69 \pm 2.4$ & $52 \pm 1.9$ & $89 \pm 1.8$ & $92 \pm 1.9$ & $81 \pm 0.5$ \\
\hline 2 & 20 & $65 \pm 1.3$ & $83 \pm 1.1$ & $58 \pm 1.4$ & $97 \pm 0.2$ & $100 \pm 0.6$ & $89 \pm 1.9$ \\
\hline 2 & 10 & $64 \pm 1.9$ & $80 \pm 1.8$ & $56 \pm 2.1$ & $95 \pm 0.9$ & $97 \pm 0.3$ & $86 \pm 0.6$ \\
\hline 3.5 & 30 & $62 \pm 0.9$ & $79 \pm 1.3$ & $57 \pm 1.6$ & $94 \pm 1.0$ & $99 \pm 0.7$ & $88 \pm 1.3$ \\
\hline 5 & 30 & $58 \pm 1.5$ & $71 \pm 0.9$ & $54 \pm 0.4$ & $90 \pm 0.8$ & $94 \pm 0.9$ & $82 \pm 0.8$ \\
\hline 5 & 30 & $59 \pm 1.7$ & $70 \pm 1.2$ & $54 \pm 0.7$ & $91 \pm 1.1$ & $94 \pm 1.2$ & $83 \pm 1.4$ \\
\hline 2 & 10 & $63 \pm 1.8$ & $79 \pm 1.4$ & $56 \pm 1.3$ & $95 \pm 0.4$ & $98 \pm 2.4$ & $87 \pm 1.1$ \\
\hline 3.5 & 10 & $58 \pm 0.5$ & $74 \pm 0.7$ & $53 \pm 1.2$ & $91 \pm 0.9$ & $96 \pm 0.9$ & $84 \pm 0.8$ \\
\hline 2 & 30 & $67 \pm 0.7$ & $96 \pm 0.9$ & $62 \pm 1.9$ & $97 \pm 0.7$ & $101 \pm 1.2$ & $92 \pm 0.7$ \\
\hline 5 & 20 & $55 \pm 1.0$ & $70 \pm 2.1$ & $52 \pm 0.8$ & $90 \pm 1.3$ & $93 \pm 0.8$ & $80 \pm 0.7$ \\
\hline 5 & 10 & $55 \pm 0.8$ & $67 \pm 0.7$ & $50 \pm 1.7$ & $87 \pm 2.1$ & $92 \pm 2.1$ & $78 \pm 1.1$ \\
\hline 5 & 30 & $59 \pm 1.3$ & $70 \pm 0.4$ & $53 \pm 0.8$ & $92 \pm 0.8$ & $93 \pm 1.5$ & $83 \pm 0.8$ \\
\hline 5 & 10 & $54 \pm 1.2$ & $67 \pm 0.8$ & $50 \pm 2.2$ & $88 \pm 1.9$ & $91 \pm 1.1$ & $78 \pm 2.1$ \\
\hline
\end{tabular}

HCl: Hydrochloride, ER: Extended release, TEC: Triethyl citrate

variables and responses for all experimental runs are given in Table 2. Models of various responses were obtained using Design Expert (Stat-Ease). The values of $R^{2}$, adjusted $R^{2}$ and predicted $R^{2}$ were shown in Tables 3-5, for each response along with their ANOVA results. Values of probability $P<0.05$ represent significant model terms. After elimination of nonsignificant $(P>0.05)$ coefficients in Tables 3-5, following correlations for response variables were obtained in terms of coded factors. The regression equations carry factors along with coefficients (positive/negative) which quantify response values. A positive sign of coefficient indicates synergistic effects, whereas negative sign represents an antagonistic effect.

All the responses observed for various formulations were fitted simultaneously to first order, second order and quadratic models using Design Expert. Responses $\mathrm{Y}_{1}$ and $\mathrm{Y}_{2}$ were found to follow quadratic and second order model, respectively, for the formulations prepared employing Eudragit RSPO as ER polymer. Responses $\mathrm{Y}_{1}$ and $\mathrm{Y}_{2}$ were found to follow quadratic model for formulations prepared employing Eudragit RLPO as ER polymer. Responses $Y_{1}$ and $Y_{2}$ were found to follow linear model for formulations prepared employing Ethocel as ER polymer.

From the obtained ANOVA results [Tables 3-5], in all the cases, main factors ER polymer (Eudragit RSPO/ Eudragit RLPO/ethyl cellulose) concentration and plasticizer (TEC) concentration caused variation on drug release. The model shows that the ER polymer concentration had a negative impact on drug release whereas plasticizer concentration had positive impact on drug release. The interaction terms 
have a positive impact on $\mathrm{Y}_{1}$ from formulations fabricated with Eudragit RSPO as ER polymer, and it shown negative impact on drug release from formulations prepared with Eudragit RLPO and Ethocel as ER polymer. In case of $\mathrm{Y}_{2}$, interaction terms shown positive impact from formulations prepared with Eudragit RSPO and Eudragit RLPO as ER polymer, and negative impact from the formulations fabricated by Ethocel as ER polymer. Both responses $\left(\mathrm{Y}_{1}\right.$ and $\mathrm{Y}_{2}$ ) were decreased with increasing the ER polymer concentration and increased with increasing the plasticizer concentration.

\section{Contour and three-dimensional (3D) response surface plot analysis}

The design expert software (Stat-Ease) generated the contour and 3D surface plots are presented in Figures 2-4, which are very useful to study the interaction effects of the factors on

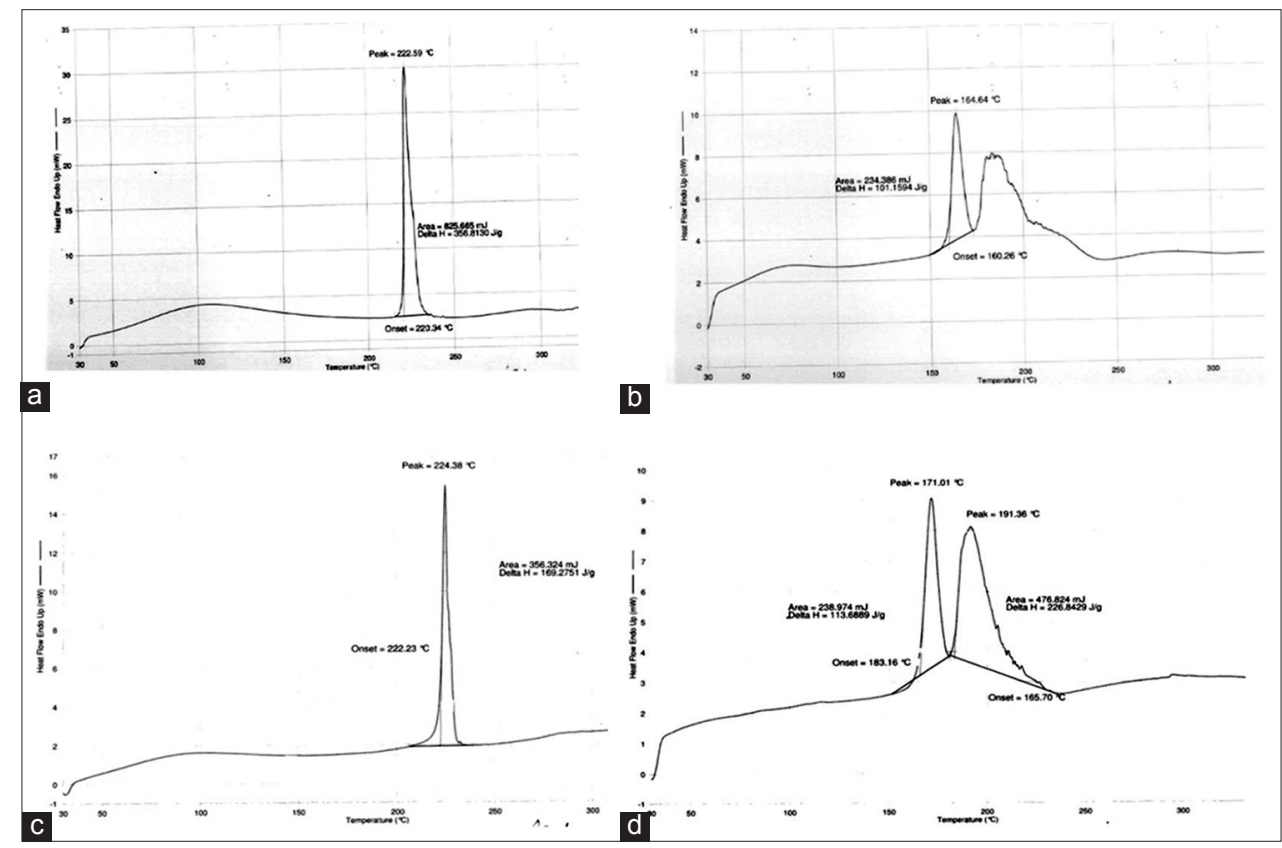

Figure 1: Differential scanning calorimetry thermograms: (a) Methylphenidate hydrochloride ( $\mathrm{HCl})$ active pharmaceutical ingredient (API)-initial; (b) methylphenidate $\mathrm{HCl}$ composite blend - Initial, (c) methylphenidate $\mathrm{HCl} \mathrm{API}-4$ weeks at $40^{\circ} \mathrm{C} / 75 \%$ $\mathrm{RH}$, (d) methylphenidate $\mathrm{HCl}$ composite blend-4 weeks at $40^{\circ} \mathrm{C} / 75 \% \mathrm{RH}$

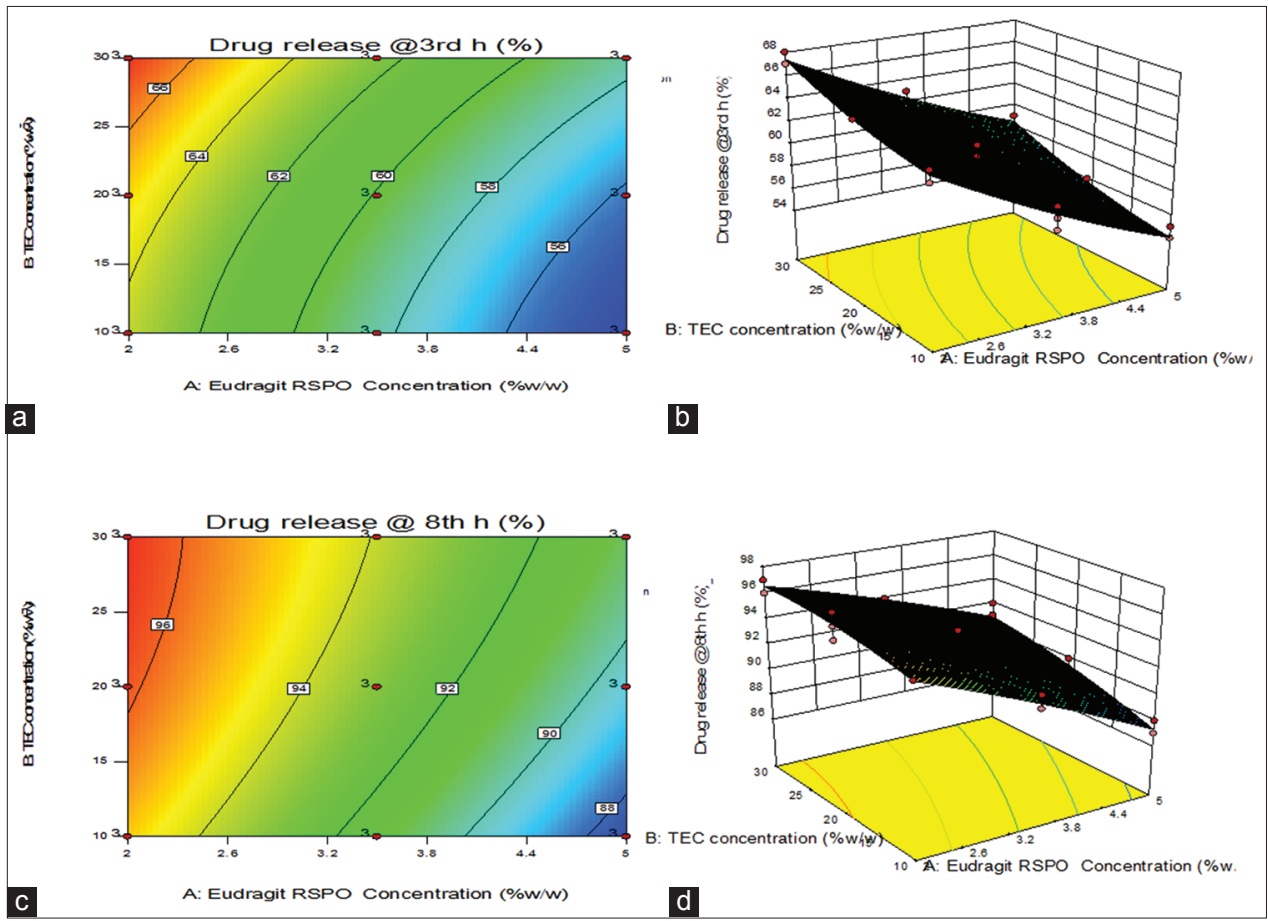

Figure 2: Contour plots ( $a$ and $c$ ) and response surface plots ( $b$ and $d$ ) showing the impact of factors (concentration of Eudragit $\mathrm{RSPO}$ and triethyl citrate) on $\%$ drug release at $3^{\text {rd }}$ and $8^{\text {th }} \mathrm{h}$ 


\begin{tabular}{|c|c|c|c|c|c|c|}
\hline Source & b-coefficient & Sum of squares & df & Mean square & $F$ value & $P$ value, $P>F$ \\
\hline \multicolumn{7}{|l|}{$Y 1(\%)$} \\
\hline Model & 72.03704 & 462.11 & 5 & 92.42 & 226.85 & $<0.0001$ \\
\hline$X_{1}$ & -4.85185 & 382.72 & 1 & 382.72 & 939.41 & $<0.0001$ \\
\hline$x_{2}$ & -0.033333 & 76.06 & 1 & 76.06 & 186.68 & $<0.0001$ \\
\hline$X_{1} X_{2}$ & 0.011111 & 0.33 & 1 & 0.33 & 0.82 & 0.3760 \\
\hline$X_{1}^{2}$ & 0.22222 & 1.50 & 1 & 1.50 & 3.68 & 0.0687 \\
\hline$X_{2}^{2}$ & 5.00000 & 1.50 & 1 & 1.50 & 3.68 & 0.0687 \\
\hline Residual error & & 8.56 & 21 & 0.41 & & \\
\hline Pure error & & 6.67 & 18 & 0.37 & & \\
\hline Total & & 470.67 & 26 & & & \\
\hline \multicolumn{7}{|c|}{$R^{2}=0.9818 ;$ adjusted $R^{2}=0.9775 ;$ predicted $R^{2}=0.9703$} \\
\hline \multicolumn{7}{|c|}{$Y_{2}(\%)$} \\
\hline Model & 100.18519 & 232.39 & 3 & 77.46 & 179.83 & $<0.0001$ \\
\hline$x_{1}$ & -2.88889 & 200.00 & 1 & 200.00 & 464.30 & $<0.0001$ \\
\hline$x_{2}$ & 0.011111 & 29.39 & 1 & 29.39 & 68.23 & $<0.0001$ \\
\hline$X_{1} X_{2}$ & 0.033333 & 3.00 & 1 & 3.00 & 6.96 & 0.0147 \\
\hline Residual error & & 9.91 & 23 & 0.43 & & \\
\hline Pure error & & 8.00 & 18 & 0.44 & & \\
\hline Total & & 242.30 & 26 & & & \\
\hline \multicolumn{7}{|c|}{$R^{2}=0.9591 ;$ adjusted $R^{2}=0.9538 ;$ predicted $R^{2}=0.9445$} \\
\hline \multicolumn{7}{|c|}{$\begin{array}{l}\text { Regression equation of the fitted model": } Y_{1}(\%)=72.03704-4.85185^{*} X_{1}-0.033333^{*} X_{2} ; Y_{2}(\%)=100.18519-2.88889^{*} \\
X_{1}+0.011111^{\star} X_{2}+0.033333^{\star} X_{1} X_{2}\end{array}$} \\
\hline
\end{tabular}

responses. This type of the plot visualizes the effects of two factors on the response at a time. Figures 2 and 4 exhibit a curvilinear relationship with $\mathrm{Y}_{1}$ and $\mathrm{Y}_{2}$ whereas Figure 3 shown curvilinear relationship with $\mathrm{Y}_{1}$ and nonlinear relationship with $\mathrm{Y}_{2}$.

The data of $\%$ drug release at $3^{\text {rd }}$ and $8^{\text {th }} \mathrm{h}$ for all batches executed with Eudragit RSPO as ER coating polymer ranges from $54-68 \%$ to $87-97 \%$, respectively. The drug release from these formulations was well around the predetermined specifications. The data of $\%$ drug release at $3^{\text {rd }}$ and $8^{\text {th }} \mathrm{h}$ for all batches executed with Eudragit RLPO as ER coating polymer ranges from $67-85 \%$ to $90-101 \%$, respectively. At $5 \% \mathrm{w} / \mathrm{w}$ concentration also Eudragit RLPO fails to provide a controlled release. The data of $\%$ drug release at $3^{\text {rd }}$ and $8^{\text {th }} \mathrm{h}$ for all batches executed with Ethocel as ER coating polymer ranges from $50-61 \%$ to $78-92 \%$, respectively. The retarded drug release was observed with ethocel at $2 \% \mathrm{w} / \mathrm{w}$ concentration also.

Among the studied range, the concentration of $3.5 \% \mathrm{w} / \mathrm{w}$ Eudragit RSPO with $20 \% \mathrm{w} / \mathrm{w}$ TEC concentration has shown drug release at both $3^{\text {rd }}$ and $8^{\text {th }} \mathrm{h}$ well within the predetermined specifications [Figure 5]. The drug release profile of optimized formulation is presented in Figure 6.

\section{Evaluation of pellets}

\section{Micromeretic properties}

The bulk and tapped density of batches range from 0.64-0.67 to $0.72-0.80 \mathrm{~g} / \mathrm{cc}$, respectively. The Hausner's ratio values (1.046-1.075) indicated good flow properties according to USP limits.

\section{Assay}

The assay of the all formulations was tested, and results were found in the range of $98.2-100.9 \%$. Assay of the optimized formulation was observed to be $99.7 \%$.

\section{Drug release kinetics}

The dissolution data of optimized formulation fitted into kinetic models, the obtained results concluded that the drug release followed the first order kinetics as $R^{2}$ values were higher for first order model (0.962) than zero order model 
Mukkala, et al.: Multiparticulate drug delivery systems of methylphenidate hydrochloride

Table 4: ANOVA results for predicting \% drug release at $3^{\text {rd }}$ and $8^{\text {th }} \mathrm{h}$ employing Eudragit RLPO as ER polymer

\begin{tabular}{|c|c|c|c|c|c|c|}
\hline Source & b-coefficient & Sum of squares & df & Mean square & $F$ value & $P$ value, $P>F$ \\
\hline \multicolumn{7}{|l|}{$Y_{1}(\%)$} \\
\hline Model & 77.43210 & 979.37 & 5 & 195.87 & 541.76 & $<0.0001$ \\
\hline$X_{1}$ & -0.46914 & 854.22 & 1 & 854.22 & 2362.65 & $<0.0001$ \\
\hline$X_{2}$ & 0.61111 & 112.50 & 1 & 112.50 & 311.16 & $<0.0001$ \\
\hline$X_{1} X_{2}$ & -0.033333 & 3.00 & 1 & 3.00 & 8.30 & 0.0090 \\
\hline$X_{1}^{2}$ & -0.49383 & 7.41 & 1 & 7.41 & 20.49 & 0.0002 \\
\hline$X_{2}^{2}$ & -6.11111 & 2.24 & 1 & 2.24 & 6.20 & 0.0213 \\
\hline Residual error & & 7.59 & 21 & 0.36 & & \\
\hline Pure error & & 6.00 & 18 & 0.33 & & \\
\hline Total & & 986.96 & 26 & & & \\
\hline \multicolumn{7}{|c|}{$R^{2}=0.9923 ;$ adjusted $R^{2}=0.9905 ;$ Predicted $R^{2}=0.9872$} \\
\hline \multicolumn{7}{|c|}{$Y_{2}(\%)$} \\
\hline Model & 90.77160 & 262.68 & 5 & 52.54 & 79.70 & $<0.0001$ \\
\hline$X_{1}$ & 4.09877 & 193.39 & 1 & 193.39 & 293.38 & $<0.0001$ \\
\hline$X_{2}$ & 0.22500 & 43.56 & 1 & 43.56 & 66.08 & $<0.0001$ \\
\hline$X_{1} X_{2}$ & 5.55556 & 0.083 & 1 & 0.083 & 0.13 & 0.7257 \\
\hline$X_{1}^{2}$ & -0.91358 & 25.35 & 1 & 25.35 & 38.46 & $<0.0001$ \\
\hline$X_{2}^{2}$ & -2.2222 & 0.30 & 1 & 0.30 & 0.45 & 0.5099 \\
\hline Residual error & & 39.491 & 21 & 0.66 & & \\
\hline Pure error & & 10.0000 & 18 & 0.56 & & \\
\hline Total & & 276.519 & 26 & & & \\
\hline
\end{tabular}

$R^{2}=0.9499$; adjusted $R^{2}=0.9380$; predicted $R^{2}=0.9161$

Regression equation of the fitted model\#:

$Y_{1}(\%)=77.43210-0.46914^{\star} X_{1}+0.61111^{\star} X_{2}-0.033333^{\star} X_{1} X_{2}-0.49383^{\star} X_{1}{ }^{2}-6.11111^{\star} X_{2}^{2} ; Y_{2}(\%)=90.77160+4.09877^{\star}$ $X_{1}+0.22500^{\star} X_{2}-0.91358^{\star} X_{1}^{2}$

${ }^{*} P<0.05$ considered as significant. "Only the terms with statistical significance are included. $X_{1}$ : Eudragit RLPO concentration, $X_{2}$ : TEC concentration, ANOVA: Analysis of variance, ER: Extended release, TEC: Triethyl citrate

\begin{tabular}{|c|c|c|c|c|c|c|}
\hline Source & b-coefficient & Sum of squares & df & Mean square & $F$ value & $P$ value, $P>F$ \\
\hline \multicolumn{7}{|l|}{$Y_{1}(\%)$} \\
\hline Model & 58.53704 & 252.50 & 2 & 126.25 & 340.17 & $<0.0001$ \\
\hline$X_{1}$ & -2.11111 & 180.50 & 1 & 180.50 & 486.34 & $<0.0001$ \\
\hline$X_{2}$ & 0.20000 & 72.00 & 1 & 72.00 & 194.00 & $<0.0001$ \\
\hline Residual error & & 8.91 & 24 & 0.37 & & \\
\hline Pure error & & 6.00 & 18 & 0.33 & & \\
\hline Total & & 261.41 & 26 & & & \\
\hline \multicolumn{7}{|c|}{$R^{2}=0.9659 ;$ adjusted $R^{2}=0.9631 ;$ predicted $R^{2}=0.9572$} \\
\hline \multicolumn{7}{|c|}{$Y_{2}(\%)$} \\
\hline Model & 90.90741 & 435.61 & 2 & 217.81 & 577.25 & $<0.0001$ \\
\hline$X_{1}$ & -2.92593 & 346.72 & 1 & 346.72 & 918.92 & $<0.0001$ \\
\hline$X_{2}$ & 0.22222 & 88.89 & 1 & 88.89 & 235.58 & $<0.0001$ \\
\hline Residual error & & 9.06 & 24 & 0.38 & & \\
\hline
\end{tabular}

$($ Contd...) 


\begin{tabular}{lcccccc} 
& \multicolumn{2}{c}{ Table 5: (Continued) } & df & Mean square & $\boldsymbol{F}$ value & $\boldsymbol{P}$ value, $\boldsymbol{P}>\boldsymbol{F}$ \\
\hline Source & b-coefficient & Sum of squares & df & 18 & 0.30 & \\
Pure error & 5.33 & 26 & &
\end{tabular}

$R^{2}=0.9796 ;$ adjusted $R^{2}=0.9779 ;$ predicted

$R^{2}=0.9738$

Regression equation of the fitted model\#: $Y_{1}(\%)=58.53704-2.11111^{\star} X_{1}+0.20000^{\star} X_{2} ; Y_{2}(\%)=90.90741-2.92593^{\star}$ $X_{1}+0.22222^{*} X_{2}$

${ }^{*} P<0.05$ considered as significant. "Only the terms with statistical significance are included. $X_{1}$ : Ethocel (ethyl cellulose) concentration, $X_{2}$ : TEC concentration, ANOVA: Analysis of variance, ER: Extended release, TEC: Triethyl citrate

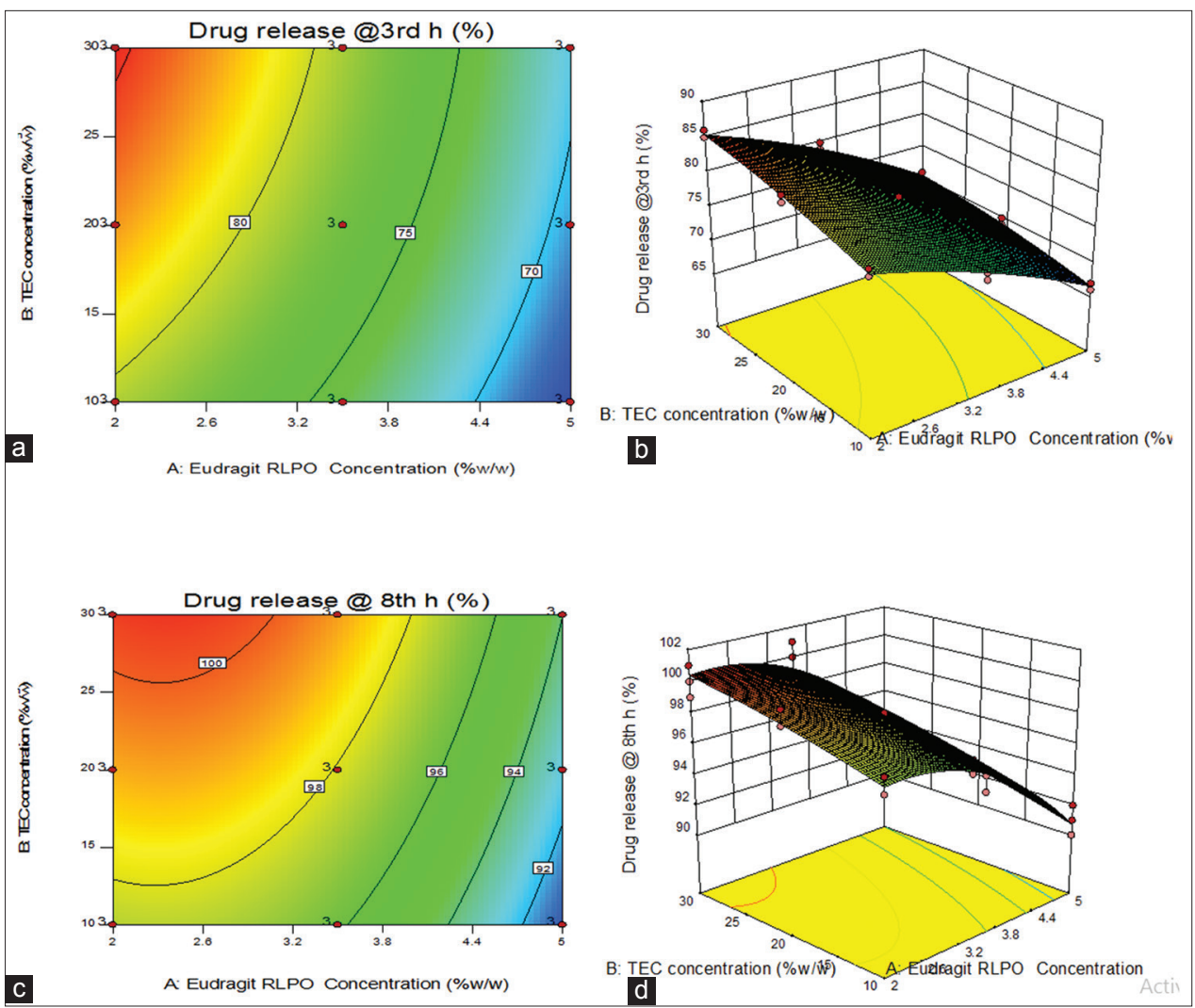

Figure 3: Contour plots ( $a$ and c) and response surface plots (b and d) showing the impact of factors (concentration of Eudragit RLPO and triethyl citrate) on \% drug release at $3^{\text {rd }}$ and $8^{\text {th }} \mathrm{h}$

(0.768). The $n$ value is $<0.45(0.261)$; hence, the mechanism of drug release was fickian diffusion.

\section{CONCLUSION}

Methylphenidate $\mathrm{HCl}$ ER pellets generating a biphasic release profile from single core were successfully fabricated by fluid bed coating technology. The effect of two independent variables (ER polymer concentration and plasticizer concentration) on two responses were studied and optimized systematically using RSM. This investigation revealed that independent variables had a significant impact on the measured responses. The quantitative effect of these factors at different levels on drug release could be predicted by polynomial equations. Linearity observed between the actual and predicted values of the response variables indicated that analytical ability of the selected design. The optimized batch showed $99.7 \%$ assay, and drug release was well within the predetermined specifications. Micromeritic properties of these pellets exhibited excellent flow properties, which are crucial to attain the uniformity 


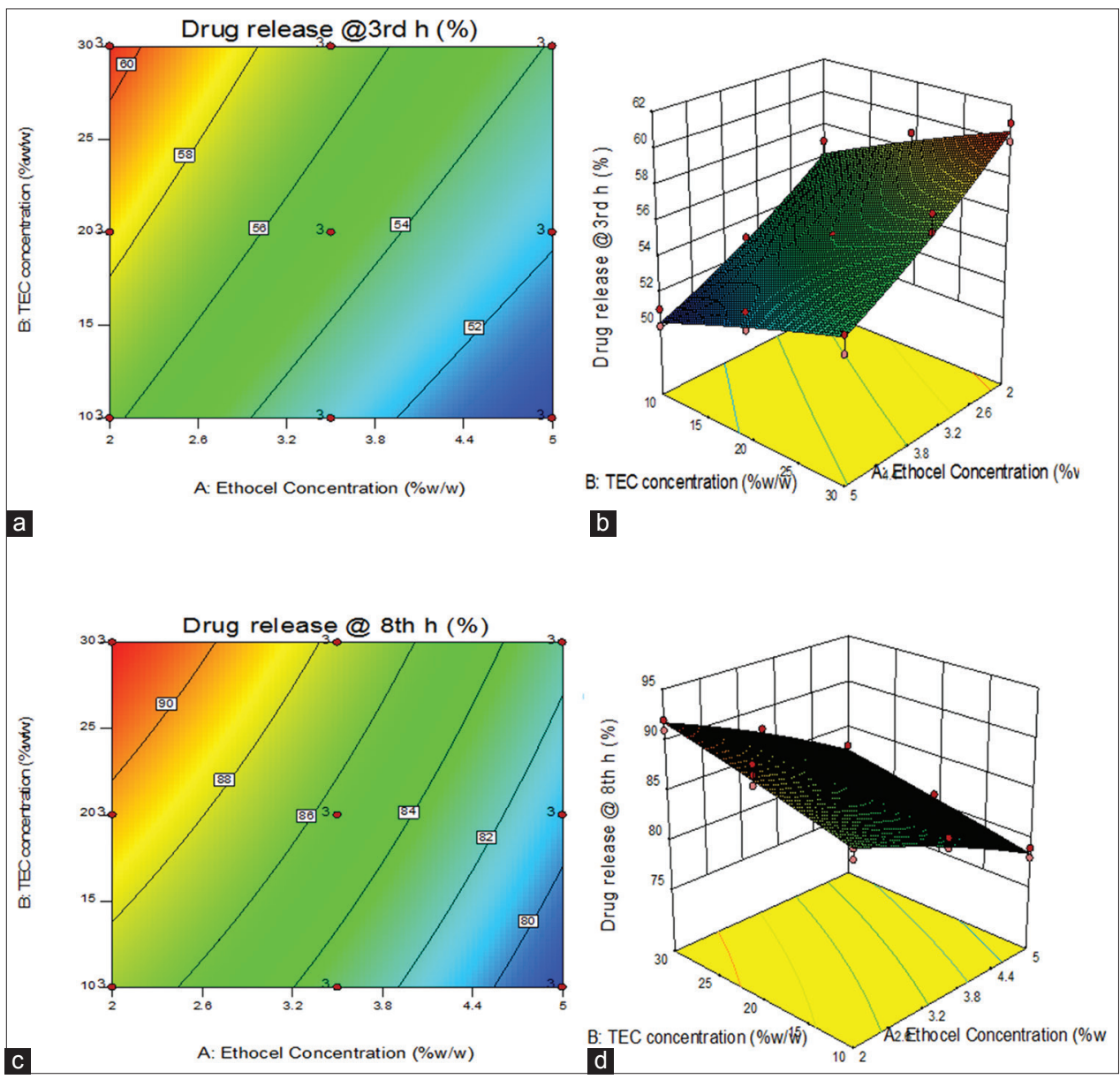

Figure 4: Contour plots $(a$ and $c$ ) and response surface plots ( $b$ and d) showing the impact of factors (concentration of ethocel and triethyl citrate) on $\%$ drug release at $3^{\text {rd }}$ and $8^{\text {th }} \mathrm{h}$

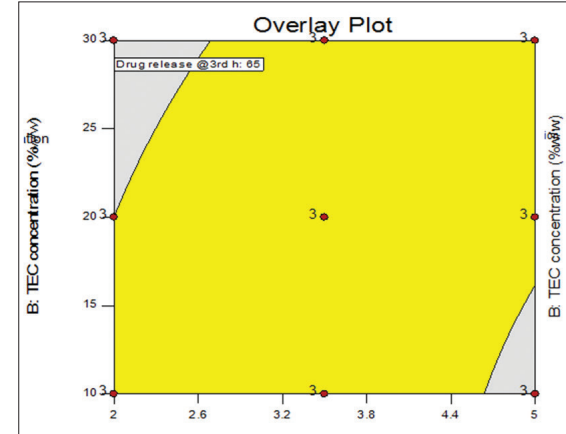

a

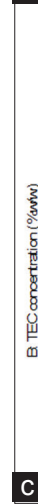

A: Eudragit RSPO Concentration (\%w/w)

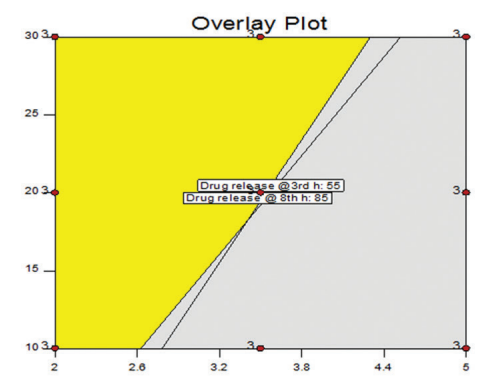

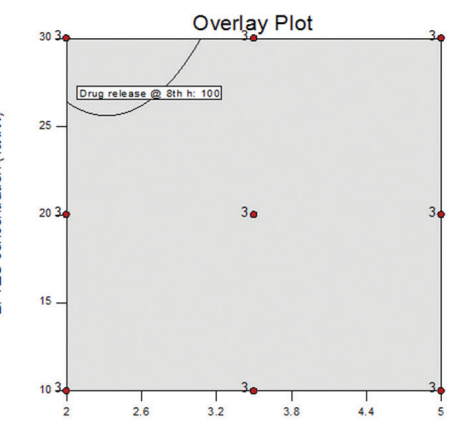

b

Figure 5: Overlay plots of: (a) Eudragit RSPO; (b) Eudragit RLPO and (c) ethocel 


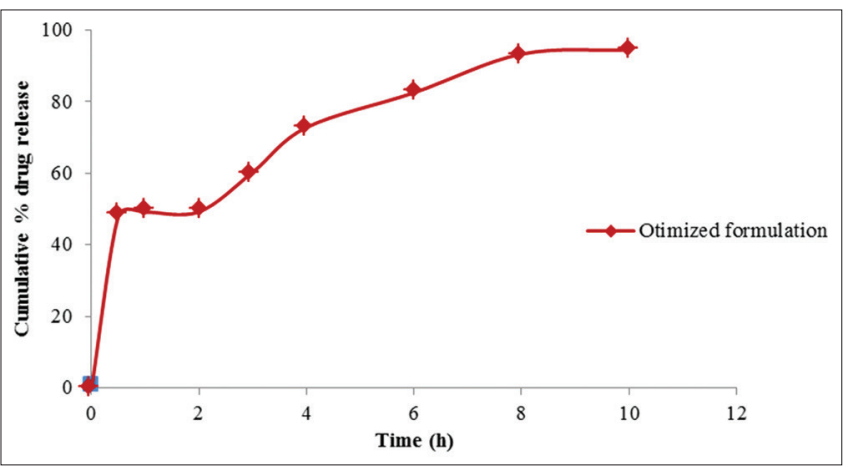

Figure 6: Dissolution profile of the optimized formulation

of dosage units in capsule filling. DSC studies evidenced that there was no interaction between drug and selected excipients. The optimized formulation can be used as an alternative to the marketed formulation. Hence, the applicability of RSM to optimize the formulation variables in the fabrication of methylphenidate $\mathrm{HCl}$ ER pellets is apt enough.

\section{ACKNOWLEDGMENTS}

Authors are thankful to RA Chem Pharma Ltd, Hyderabad, for providing the gift sample of methylphenidate $\mathrm{HCl}$, polymers and facilities to carry out the research work.

\section{REFERENCES}

1. Gehbre Sellasie I. Pellets: A General Overview: Pharmaceutical Pelletization Technology. $1^{\text {st }}$ ed. New York: Marcel Dekker Inc.; 1989.

2. Hiren PP, Patel JK, Ravi RP, Manish PP. Pellets: A general overview. Int J Pharm World Res 2010;1:1-15.
3. Shajahan A, Anil VC, Sunil BJ. A flexible technology for modified-release drugs: Multiple unit pellets system. J Control Release 2010;147:2-16.

4. International Conference on Harmonization (ICH). Guidance for Industry: Q8 (R2) Pharmaceutical Development, ICH Harmonized Tripartite Guideline. Geneva: ICH; 2009.

5. Dayal P, Pillay V, Babu RJ, Singh M. Box-Behnken experimental design in the development of a nasal drug delivery system of model drug hydroxyurea: Characterization of viscosity, in vitro drug release, droplet size and dynamic surface tension. AAPS PharmSciTech 2005;6:E573-85.

6. Staufer WB, Greydanus DE. Attention deficit/ hyperactivity disorder pshychopharmacology for college students. Pediatr Clin North Am 2005;52:71-84, viii.

7. Bolton S. Statistical applications in the pharmaceutical sciences. In: Lachman L, Lieberman HA, Kanig JL, editors. The Theory and Practice of Industrial Pharmacy. $3^{\text {rd }}$ ed. Bombay: Varghese Publishing House; 1987. p. 243-89.

8. Indian Pharmacopoeia Commission. Pharmacopoeia I. Vol. 2. Ghaziabad, India: Indian Pharmacopoeia Commission; 2010. p. 786.

9. United States Pharmacopeial Convention, Inc. Methylphenidate Hydrochloride Tablets; U.S. Pharmacopoeia-National Formulary [USP 29 NF 24]. USA: United States Pharmacopeial Convention, Inc.; 2014. p. 1406.

10. Available from: https://www.accessdata.fda.gov/scripts/ cder/dissolution/dsp_SearchResults.cfm. [Last accessed on 2017 Jun 20].

11. Dash S, Murthy PN, Nath L, Chowdhury P. Kinetic modeling on drug release from controlled drug delivery systems. Acta Pol Pharm 2010;67:217-23.

Source of Support: Nil. Conflict of Interest: None declared. 